\title{
Tree Sway Time Series of 7 Amazon Tree Species (July 2015-May 2016)
}

\author{
Tim van Emmerik ${ }^{1 *}$, Susan Steele-Dunne ${ }^{1}$, Marceau Guerin ${ }^{2}$, Pierre Gentine ${ }^{2}$, \\ Rafael Oliveira ${ }^{3}$, Rolf Hut ${ }^{1}$, John Selker ${ }^{4}$, Jim Wagner $^{5}$ and Nick van de Giesen ${ }^{1}$ \\ ${ }^{1}$ Water Resources Section, Delft University of Technology, Delft, Netherlands, ${ }^{2}$ Department of Earth and Environmental \\ Engineering, Columbia University, New York, NY, United States, ${ }^{3}$ Department of Plant Biology, Institute of Biology, University \\ of Campinas, Campinas, Brazil, ${ }^{4}$ Department of Biological and Ecological Engineering, Oregon State University, Corvallis, \\ OR, United States, ${ }^{5}$ Oregon Research Electronics, Tangent, OR, United States
}

Keywords: tree physiology, acceleration, Amazon, drag coefficient, turbulence, interception, water stress

\section{INTRODUCTION}

Trees are a crucial part of ecosystems through their important influence on the water and carbon cycles (Reichstein et al., 2013; Schlesinger and Jasechko, 2014; Patton et al., 2016). They play a key role in hydrological and ecological systems, and land-surface interactions. Ground measurements of tree properties and tree-related fluxes can quantify, for example, tree mass variations, $\mathrm{CO}_{2}$ uptake, transpiration, rainfall interception and canopy drag, which are crucial parameters for understanding and modeling tree behavior and their roles in ecosystems.

OPEN ACCESS

Edited by:

Steven V. Weijs,

University of British Columbia, Canada

Reviewed by:

Joshua B. Fisher,

NASA Jet Propulsion Laboratory

(JPL), United States

Ahmed M. ElKenawy,

Mansoura University, Egypt

*Correspondence:

Tim van Emmerik

t.h.m.vanemmerik@tudelft.n!

Specialty section:

This article was submitted to

Hydrosphere,

a section of the journal

Frontiers in Earth Science

Received: 30 June 2018

Accepted: 16 November 2018

Published: 07 December 2018

Citation:

van Emmerik $T$, Steele-Dunne $S$,

Guerin M, Gentine P, Oliveira R, Hut R,

Selker J, Wagner $J$ and van de

Giesen N (2018) Tree Sway Time

Series of 7 Amazon Tree Species (July

2015-May 2016)

Front. Earth Sci. 6:221.

doi: 10.3389/feart.2018.00221
Unfortunately, tree measurement sensors are often based on invasive techniques (e.g. sap flow sensors or dendrometers), unable to withstand challenging field conditions (e.g. weathering or power/electronical failure due to climate), or cannot measure all parameters of interest.

Accelerometers offer an economic and robust way for obtaining data series of tree motion, which has been used to infer tree properties and tree-related fluxes. Mounted on a tree trunk, they measure tree sway, which is determined by its mass, elasticity, wood density and drag coefficient. These parameters can in turn be related to water-related mass changes (transpiration and water uptake) (Llamas et al., 2013), biomass-related mass changes (growth, leaf fall and leaf flush) (Selker et al., 2011), tree-atmosphere interactions (drag coefficient and momentum transfer) (van Emmerik et al., 2018a). Additionally, tree sway has shown to be related to tree throw failure mechanisms, and thereby help to reduce storm risks of trees and forests (Flesch and Wilson, 1999a,b; Wilson and Flesch, 1999), by assessing the influence of forest cutblocks.

The relation between tree sway and tree properties and tree-related fluxes can be derived from (1) Newton's second law, and (2) a momentum balance. First, it is often assumed that trees behave like damped harmonic oscillators (Gardiner, 1995; Peltola, 1996). In that case, the tree's natural frequency is linked to mass and elasticity through:

$$
\omega_{0}=2 \pi f_{0}=\sqrt{\frac{k}{m}}
$$

With natural frequency in $[\mathrm{rad} / \mathrm{s}] \omega_{0}$, natural frequency in $[\mathrm{Hz}] f_{0}$, mass $m$ and elasticity $k$. From the frequency spectrum of tree acceleration the natural frequency can be determined. Second, following the momentum balance the frequency spectrum of tree sway $P_{y}(f)$ as a function of frequency can be expressed as (Amtmann, 1985; Mayer, 1987):

$$
P_{y}(f)=H_{m}(f)^{2} \rho_{a}^{2} C_{d}^{2} A_{2} u^{2} H_{a}(f) P_{u}(f)
$$

With mechanical transfer function $H_{m}(f)$, air density $\rho_{a}$, drag coefficient $C_{d}$, wind speed $u$, aerodynamic transfer function $H_{a}(f)$ and wind load frequency spectrum $P_{u}(f)$. 
These relations have been used in previous tree-related research. Moore and Maguire (2004) showed that factors such as branch removal and snow loading influences tree natural frequency. Mayer (1987) used tree sway data to demonstrate that the primary sway (i.e., the system as a whole) is related to tree throw. Flesch and Wilson (1999a,b) and Wilson and Flesch (1999) used tilt sensors to analyze tree sway, and assess the influence of management techniques on the possible reduction on wind throw. Later, Moore and Maguire (2005) empirically found a relationship between tree height and tree natural frequency. These, and many more, studies already demonstrated the use of tree sway data. In particular the derived estimation of tree natural frequency is useful for risk assessment of wind damage/throw, and quantification of tree properties (e.g., mass, elasticity) and responses (e.g., intercepted precipitation, mass changed in response to water stress).

Data in previous studies were mainly obtained for several hours, or in rare cases days. Our dataset presents a unique opportunity to use long-term tree sway data of 19 individual trees. This allows analysis of diurnal and seasonal changes, as well as comparison between individuals of the same species, and between different species as a whole. In this paper we describe the details of the obtained dataset, and discuss current and potential applications of the dataset.

\section{DATA COLLECTION}

\subsection{Measurement Location}

All data were collected around the K34 observatory $(130 \mathrm{~m}$ above Mean Sea Level) in the Amazon rainforest $\left(2.6085^{\circ} \mathrm{S}\right.$, $60.2093^{\circ} \mathrm{W}$ ), $60 \mathrm{~km}$ Northwest of Manaus, Brazil (see van Emmerik et al., 2017). A map of the measurement location, including the measured trees and the K34 observatory is presented in Figure 1A. The study area is characterized by a wet tropical climate. Additional meteorological, hydrological and plant physiological data may be obtained from the K34 observatory, managed by the National Institute of Amazonian Research (INPA).

\subsection{Plant Material}

Accelerometers were mounted on 19 individual trees, covering seven different species with one to four individuals per species. The trees were selected to cover a broad range of estimated wood density, tree height, and diameter at breast height (DBH). Table 1 presents an overview of the measured trees. Tree species were classified by a taxonomist on site. Wood density was estimated using the Global Wood Density Database (Chave et al., 2009; Zanne et al., 2009). Tree height was measured using measurement tape during installation of the accelerometers.

\subsection{Sensor Description}

All accelerometers used were of the type Acceleration Logger Model AL100 (Oregon Research Electronics, Tangent, OR, USA), which is specifically designed to be physically robust and water proof. Robustness is achieved through a casing that prevents water and organisms to reach the sensor. The sensor has internal batteries and data storage, so no (wire) connections are required during measurements. Consequently, its dimensions $(14.5 \times 9.2$ $\times 5.5 \mathrm{~cm}, 0.4 \mathrm{~kg}$ ) are larger than other available accelerometers. The accelerometers can measure acceleration in three axis with a frequency up to $25 \mathrm{~Hz}$. Depending on the sampling rate and environmental conditions, it can log for several months on two C-size cell batteries. Data are stored on regular microSD cards. For example, with a $8 \mathrm{~GB}$ data card it can store up to 320 days of data measured with a frequency of $10 \mathrm{~Hz}$. Data are written to a newly created file each day to minimize data loss in case of empty batteries, full data storage, or other potential failures. The casing has space to include several silica bags to absorb moisture when installed in humid environments.

\subsection{Measurement Setup}

The accelerometers were placed on the tree trunk, right below the point of main branching. This guaranteed the largest excitation of the sensor, and therefore largest acceleration values, that were still representative for the whole tree. Installing accelerometers on the primary of secondary branches comes with the risk of mainly measuring higher order effects. The accelerometers were mounted using a spring around the trunk. This allows some expansion of the tree when growing, and also assures a rigid attachment to the tree. All measurements were done with a sampling frequency of $10 \mathrm{~Hz}$.

\section{DATA DESCRIPTION}

The available dataset includes raw acceleration values for all three dimensions as measured by the sensor with a frequency of $10 \mathrm{~Hz}$. In Table 1 it can be found which accelerometer (serial numbers SN1001-SN1019) was mounted on which specific tree. For each sensor, data are available per day. This reduces computational needs, as each daily file can be read and processed individually.

As most applications require transformation of the data from the time to frequency domain, an additional dataset of the acceleration data in the frequency domain can be downloaded. For each sensor, files are available that contain time series of the acceleration in the frequency domain. These were produced by applying a Fast Fourier Transform (FFT) on 30 min of horizontal (y-axis) acceleration with a moving window of $10 \mathrm{~min}$. Figure $\mathbf{1 B}$. illustrates a typical frequency spectrum estimated using tree acceleration. It can be seen that the natural frequency around $0.2 \mathrm{~Hz}$ can be estimated well. In this example, even higher order resonance peaks are visible.

When applying the FFT to the whole dataset, a time series of the frequency spectrum is created Figures 1C-E. show a typical time series of the frequency spectrum for two trees. It can be seen that when wind speed is higher than a certain threshold, the resonance peaks are activated. It can also be seen that there are slight differences in timing and magnitude of the frequency spectra, indicating that tree specific information can be deduced. Note that this figure only shows a subset of the total available data. The complete measurement period stretches from July 2015 to May 2016.

For all applications so far (van Emmerik et al., 2017, 2018a), data have been processed using a FFT. We show that using a simple FFT the natural frequency can already be determined. 

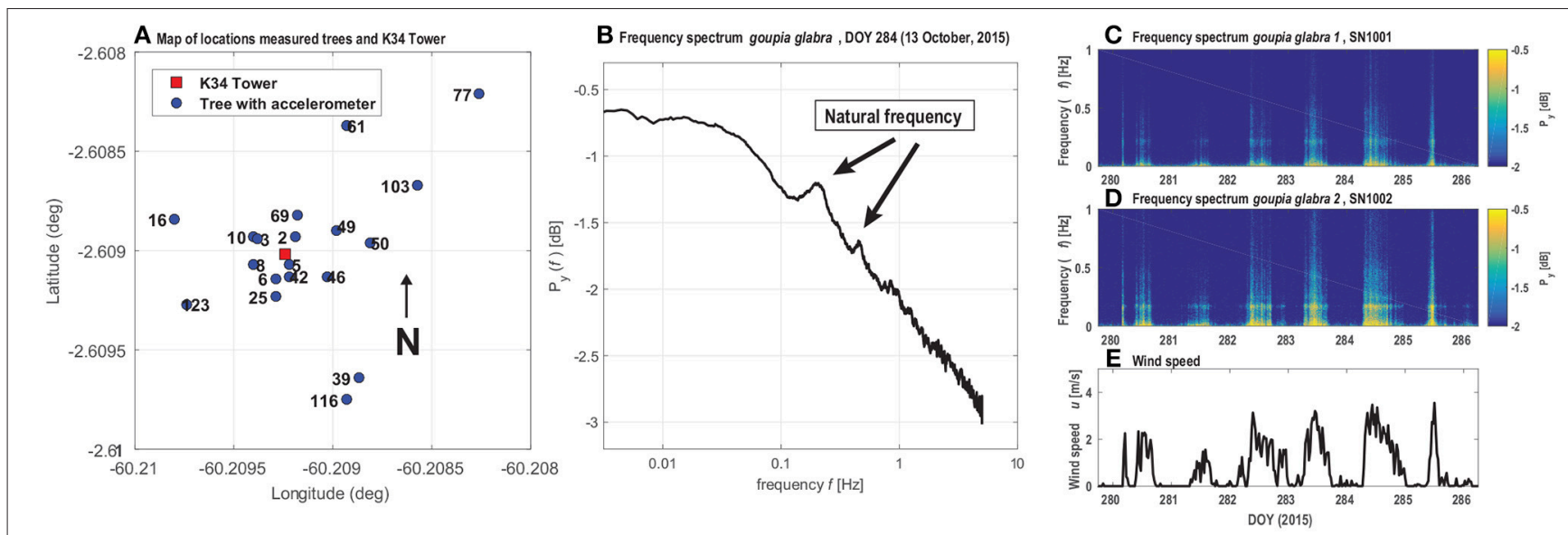

FIGURE 1 | (A) Map with the locations of the measured trees, includin gthe K34 tower, (B) Example of frequency spectrum estimated from acceleration data, (C,D) example of frequency spectrum time series of two trees in combination with (E) wind speed.

TABLE 1 | List of measured tree individuals, including acceleration sensor number, estimated wood density, estimated tree height and diameter at breast height (DBH).

\begin{tabular}{|c|c|c|c|c|c|}
\hline \multirow[t]{2}{*}{ Accelerometer } & \multirow[t]{2}{*}{ Species } & \multicolumn{2}{|c|}{ Estimated wood density } & \multirow[t]{2}{*}{ Estimated height [m] } & \multirow[t]{2}{*}{$\mathrm{DBH}[\mathrm{cm}]$} \\
\hline & & {$\left[10^{3} \mathrm{~kg} / \mathrm{m}^{3}\right]$} & High - Low & & \\
\hline SN1001 & Goupia glabra & 0.7 & High & 25 & 242.5 \\
\hline SN1002 & Goupia glabra & 0.7 & High & 32 & 208 \\
\hline SN1003 & Goupia glabra & 0.7 & High & 32 & 135 \\
\hline SN1004 & Lecythis prancei & 0.875 & Intermediate & 24 & 112 \\
\hline SN1005 & Lecythis prancei & 0.875 & Intermediate & 35 & 116.5 \\
\hline SN1006 & Lecythis prancei & 0.875 & Intermediate & 24 & 108.4 \\
\hline SN1007 & Scleronema micranthum & $0.5-0.7$ & Low & 38 & 127 \\
\hline SN1008 & Scleronema micranthum & $0.5-0.7$ & Low & 28 & 189.5 \\
\hline SN1019 & Scleronema micranthum & $0.5-0.7$ & Low & 26 & 81 \\
\hline SN1010 & Eschweilera sp. & 0.8 & Intermediate & 20 & 93.5 \\
\hline SN1009 & Eschweilera coriacea & 0.8 & Intermediate & 21 & 268 \\
\hline SN1011 & Eschweilera coriacea & 0.8 & Intermediate & 18 & 92.4 \\
\hline SN1012 & Eschweilera coriacea & 0.8 & Intermediate & 27 & 213.5 \\
\hline SN1013 & Dipteryx odorata & 1.1 & High & 35 & 177 \\
\hline SN1014 & Dipteryx odorata & 1.1 & High & 32 & 219.5 \\
\hline SN1015 & Pouteria anomala & 0.7 & Low & 22 & 111 \\
\hline SN1016 & Maquira sclerophylla & 0.5 & Low & 30 & 264 \\
\hline SN1017 & Maquira scherophylla & 0.5 & Low & 18 & 201 \\
\hline SN1018 & Maquira scherophylla & 0.5 & Low & 35 & 90.6 \\
\hline SN1019 & Pouteria sp. & 0.7 & Low & 23 & 117.5 \\
\hline
\end{tabular}

However, we also encourage further exploration with other spectrum estimation methods, such as Welch's method or the MUSIC algorithm.

\subsection{Data Availability}

All acceleration data are available on the 4.TU Repository (doi: 10.4121/uuid:c9974180-aa9b-40b4-8dbb06d5b1fce693) (van Emmerik et al., 2018b). All files are named "/YYYY/SN10XX/ALOGzZz.csv," with year YYYY, sensor number XX and day after start of logging zzz. Data are available from July 2015 to May 2016. We invite the community to explore the dataset and combine it with for example higher resolution wind data, hydro-meteorological measurements, tree physiological data and remote sensing observations to explore potential additional applications of long-term tree acceleration data.

\section{EXAMPLES OF APPLICATIONS}

\subsection{Intercepted Precipitation}

During rainfall events precipitation is intercepted by leaves of a tree. This increases the total tree mass. Selker et al. (2011) compared the natural frequency of a tree before and after a rainfall event and found a shift in frequency. A more detailed study by van Emmerik et al. (2017) found different relations between intercepted rainfall and shift in frequency of trees. For some trees, an almost linear relation was found between the 
frequency shift and precipitation. For other trees, the relation was less obvious. This was hypothesized to be caused by (1) the location of the tree in the canopy (understory trees are less likely to intercept rainfall) and (2) by splashing of water drops during high intensity rainfall events. Accelerometers were demonstrated to be a promising new method for interception measurements. Current measurement techniques mainly focus on measuring throughfall, which requires a more extensive measurement setup with multiple rainfall sensors. However, in future measurements additional throughfall measurements might give additional insights in the accuracy of interception estimations using accelerometers. Moore and Maguire (2005) also demonstrated that tree sway measurements can be used to monitor snow cover of trees. This is not applicable to the dataset presented in this paper, but might be of interest to researcher who focus on snowy ecosystems.

\subsection{Tree Mass Variations}

Besides through rainfall and snow cover, tree mass also varies through other mechanisms, such as tree growth, changes in tree water content, or leaf fall and flush. A first analysis of the data presented in this paper, van Emmerik et al. (2017) demonstrated that, for most tree species, a relation can be found between aboveground tree biomass and natural frequency. Selker et al. (2011) presented a proof of concept that there is a difference in tree natural frequency when comparing the same tree with and without leaves. More recently, Jackson et al. (in review) demonstrated that there is a significant difference between trees during summer (with leaves) and winter (no leaves). van Emmerik (2017) and van Emmerik et al. (2018a) related changes in tree sway to water stress induced mass changes, which was hypothesized to be caused by decreasing tree water content and/or leaf fall. Future efforts might focus on using tree sway data to quantify tree mass changes on even lower time scales. With the current dataset, it might also possible to track diurnal changes in natural frequency, which could be related to changes in water content. Additional measurements of leaf water potential would allow further study of the relation between tree sway and tree mass variations.

\subsection{Drag Coefficient and Roughness Length}

Tree drag coefficient is a crucial parameter for the momentum transfer from the atmosphere to the trees. Accurate estimates of tree and canopy drag coefficient might allow better representation of the canopy in, for example, land-surface models. An approximation of tree drag coefficient was presented by van Emmerik (2017) and van Emmerik et al. (2018a), based on the assumption that during turbulent conditions, available wind energy can be estimated using Kolmogorov's theory (Kolmogorov, 1991). If actual high frequency wind speed data is available, drag coefficients can be determined under all wind conditions using equation 2 . Here it was demonstrated that aggregating tree sway data over different time scales (weekly, monthly, complete monitoring period), can give different degrees of insights. When aggregated over the complete monitoring period, a clear relation between tree sway and tree mass was found. The weekly analysis in turn demonstrated shorter term mass variations in the individual trees. A similar approach might also allow for estimating the roughness length of a forest canopy if data from multiple sensors are combined, as the variation and evolution of individual tree drag and tree-atmosphere momentum transfer can be quantified.

\subsection{Tree Damage}

Using relatively short data records, it was already shown that tree sway is related to wind throw (Mayer, 1987). Longer-term records such as those presented in this paper might allow further analysis of tree failing mechanisms. Additionally, relatively unmeasured phenomena such as tree dormancy and mortality might be further investigated.

\section{LIMITATIONS}

Besides the many potential applications of tree sway data, fundamental investigations of the role of meteorological variables (e.g., temperature, humidity, wind speed and direction, precipitation) and tree properties (e.g., mass, elasticity) on tree sway is also crucial. Many applications assume tree sway can be described as mass-spring system, or through the momentum balance in Equation (2). However, a better fundamental understanding of tree sway might open doors to even more potential applications.

As applications of long-term tree sway data are still limited, further assessments are still very dependent on the availability of other data. With the current auxiliary data we hypothesized several relations between tree sway and other processes. However, more detailed data on e.g., leaf potential, wind speed, water uptake and intercepted precipitation are required to further test our hypotheses.

One of the key assumptions of the tree selection is that the chosen trees are free standing. If they are in contact with other trees, the mechanical system is more complex and the standard approach might not be applicable. The trees in this study were selected based on visual inspection, which might have been inaccurate. Also growth of the trees might have altered the position in respect to other trees.

The optimal installation location might also be different for other tree species. The selected trees were all relavtively straight, until the point of branching off. For tree species with more complex architecture and geometry, the optimal location should be reassessed.

The presented dataset only includes tree species in the Brazilian Amazon. For tree species in other climatic regions, different relations might be found between tree sway and e.g., mass (variations), tree-atmosphere interactions and intercepted precipitation. We encourage deployment in other climatic regions to further explore the possibilities of tree sway measurements.

\section{CONCLUDING REMARKS}

Tree acceleration data have been proven to give new insights in assessing risk of tree failure, intercepted rainfall, mass variations, and tree-atmosphere interactions. To date, only relatively short datasets have been used and published (hours 
to days). Our dataset covers tree acceleration for a period of 10 months, including changing seasons, for 19 Amazon trees. We demonstrate that these data offer new opportunities of analyzing tree properties, and tree behavior in response to changing environmental conditions. We demonstrate various current applications. Yet, many potential new applications are to be explored. We encourage the scientific community to use our data to do so.

\section{AUTHOR CONTRIBUTIONS}

TvE, SS-D, MG, and RH designed the study, TvE, MG, and RO installed the sensors, all authors contributed to data analysis and writing this manuscript.

\section{REFERENCES}

Amtmann, R. (1985). "Data acquisition system for wind induced tree vibration," in The Forest-Atmosphere Interaction, eds B. A. Hutchison and B. B. Hicks (Dordrecht: Springer), 149-159.

Chave, J., Coomes, D., Jansen, S., Lewis, S. L., Swenson, N. G., and Zanne, A. E. (2009). Towards a worldwide wood economics spectrum. Ecol. Lett. 12, 351-366. doi: 10.1111/j.1461-0248.2009.01285.x

Flesch, T. K., and Wilson, J. D. (1999a). Wind and remnant tree sway in forest cutblocks.: I. Measured winds in experimental cutblocks. Agricult. For. Meteorol. 93, 229-242. doi: 10.1016/S0168-1923(98)00112-9

Flesch, T. K., and Wilson, J. D. (1999b). Wind and remnant tree sway in forest cutblocks. II. Relating measured tree sway to wind statistics. Agricult. For. Meteorol. 93, 243-258. doi: 10.1016/S0168-1923(98)00113-0

Gardiner, B. (1995). The Interactions of Wind and Tree Movement in Forest Canopies. Cambridge: Cambridge University Press.

Kolmogorov, A. N. (1991). The local structure of turbulence in incompressible viscous fluid for very large Reynolds numbers. Proc. Math. Phys. Sci. 434, 9-13. doi: 10.1098/rspa.1991.0075

Llamas, R., Niemeier, J., Kruger, A., Lintz, H., Kleinknecht, G., and Miller, R. (2013). "Diurnal cycles of tree mass obtained using accelerometers," in $A G U$ Fall Meeting Abstracts, Vol. 1 (San Francisco, CA) 1575.

Mayer, H. (1987). Wind-induced tree sways. Trees 1, 195-206. doi: $10.1007 / \mathrm{BF} 01816816$

Moore, J. R., and Maguire, D. A. (2004). Natural sway frequencies and damping ratios of trees: concepts, review and synthesis of previous studies. Trees 18, 195-203. doi: 10.1007/s00468-003-0295-6

Moore, J. R., and Maguire, D. A. (2005). Natural sway frequencies and damping ratios of trees: influence of crown structure. Trees 19, 363-373. doi: 10.1007/s00468-004-0387-y

Patton, E. G., Sullivan, P. P., Shaw, R. H., Finnigan, J. J., and Weil, J. C. (2016). Atmospheric stability influences on coupled boundary layer and canopy turbulence. J. Atmospher. Sci. 73, 1621-1647. doi: 10.1175/JAS-D-150068.1

Peltola, H. (1996). Swaying of trees in response to wind and thinning in a stand of scots pine. Boundary-Layer Meteorol. 77, 285-304. doi: 10.1007/BF001 23529

Reichstein, M., Bahn, M., Ciais, P., Frank, D., Mahecha, M. D., Seneviratne, S. I., et al. (2013). Climate extremes and the carbon cycle. Nature 500, 287-295. doi: $10.1038 /$ nature 12350

\section{FUNDING}

This work was funded by FAPESP GOAmazon project 2013/50431-2 and Vidi Grant 14126 from the Dutch Technology Foundation STW, which is part of The Netherlands Organisation for Scientific Research (NWO).

\section{ACKNOWLEDGMENTS}

We thank Ricardo Dal'Agnol and Omar Chaparro Saaveedra for providing the GPS data of the measured trees. We also thank the reviewers for their constructive comments.

Schlesinger, W. H., and Jasechko, S. (2014). Transpiration in the global water cycle. Agricult. For. Meteorol. 189, 115-117. doi: 10.1016/j.agrformet.2014. 01.011

Selker, J., Lane, J., Rupp, D., Hut, R., Abou Najm, M., Stewart, R., et al. (2011). "The answer is blowing in the wind: using wind induced resonance of trees to measure time varying canopy mass, including interception," in AGU Fall Meeting Abstracts, Vol. 1 (San Francisco, CA) 1155.

van Emmerik, T. (2017). Water Stress Detection Using Radar. PhD thesis, Delft University of Technology.

van Emmerik, T., Steele-Dunne, S., Gentine, P., Oliveira, R. S., Bittencourt, P., Barros, F., et al. (2018a). Ideas and perspectives: tree-atmosphere interaction responds to water-related stem variations. Biogeosciences 15, 6439-6449. doi: 10.5194/bg-15-6439-2018

van Emmerik, T., Steele-Dunne, S., Guerin, M., Gentine, P., Oliveira, R. S., Hut, R., et al. (2018b). Tree sway of 19 Amazon trees. Available online at: https://doi.org/ 10.4121/uuid:c9974180-aa9b-40b4-8dbb-06d5b1fce693 (Accessed June 30, 2018).

van Emmerik, T., Steele-Dunne, S., Hut, R., Gentine, P., Guerin, M., Oliveira, R. S., et al. (2017). Measuring tree properties and responses using low-cost accelerometers. Sensors 17:1098. doi: 10.3390/ s17051098

Wilson, J. D., and Flesch, T. K. (1999). Wind and remnant tree sway in forest cutblocks. III. A windflow model to diagnose spatial variation. Agricult. For. Meteorol. 93, 259-282. doi: 10.1016/S0168-1923(98) 00121-X

Zanne, A., Lopez-Gonzalez, G., Coomes, D., Ilic, J., Jansen, S., Lewis, S., et al. (2009). Global Wood Density Database. Dryad. Available online at: http://hdl. handle.net/10255/dryad235

Conflict of Interest Statement: The authors declare that the research was conducted in the absence of any commercial or financial relationships that could be construed as a potential conflict of interest.

Copyright (c) 2018 van Emmerik, Steele-Dunne, Guerin, Gentine, Oliveira, Hut, Selker, Wagner and van de Giesen. This is an open-access article distributed under the terms of the Creative Commons Attribution License (CC BY). The use, distribution or reproduction in other forums is permitted, provided the original author(s) and the copyright owner(s) are credited and that the original publication in this journal is cited, in accordance with accepted academic practice. No use, distribution or reproduction is permitted which does not comply with these terms. 